\title{
Rhegmatogenous Retinal Detachment with a High Risk of Proliferative Vitreoretinopathy Treated with Episcleral Surgery and an Intravitreal Dexamethasone 0.7-mg Implant
}

\author{
Michele Reibaldi ${ }^{\mathrm{a}} \quad$ Andrea Russo $^{\mathrm{a}}$ Antonio Longo ${ }^{\mathrm{a}}$ Vincenza Bonfiglio ${ }^{\mathrm{a}}$ \\ Maurizio G. Uva ${ }^{a}$ Caterina Gagliano ${ }^{b}$ Mario D. Toro ${ }^{a}$ \\ Teresio Avitabile ${ }^{a}$ \\ ${ }^{a}$ Department of Ophthalmology, University of Catania, and ${ }^{b}$ NEST (Neurovisual Science \\ Technology) Department of Ophthalmology, Catania, Italy
}

\section{Key Words}

Retinal detachment . Dexamethasone $0.7 \mathrm{mg} \cdot$ Ozurdex $^{\circledR}$. Proliferative vitreoretinopathy Episcleral surgery

\begin{abstract}
Purpose: To report a case of rhegmatogenous retinal detachment with a high risk of proliferative vitreoretinopathy (PVR) effectively treated with episcleral surgery and an intravitreal dexamethasone 0.7-mg implant. Methods: A 35-year-old Caucasian man with a macula-off rhegmatogenous subtotal retinal detachment that had persisted for 1 month in his myopic left eye presented several risk factors that could have led to the development of PVR after retinal detachment surgery. His best corrected visual acuity was hand motion. He received an intravitreal dexamethasone 0.7 -mg implant $\left(\mathrm{Ozurdex}^{\circledR}\right)$ after episcleral surgery to prevent this complication. Results: At least 9 months after surgery, no sign of PVR or pucker has developed in the treated eye. Visual acuity improved to 0.2 , the retina was attached and no complications were observed. Conclusion: Intravitreal dexamethasone 0.7-mg implant (Ozurdex) could be considered as off-label treatment following episcleral surgery to prevent PVR.
\end{abstract}


Reibaldi et al.: Rhegmatogenous Retinal Detachment with a High Risk of Proliferative

Vitreoretinopathy Treated with Episcleral Surgery and an Intravitreal Dexamethasone 0.7-mg Implant

\section{Introduction}

Proliferative vitreoretinopathy (PVR) is the most common cause of failure in retinal detachment surgery [1]. It can occur in untreated eyes or after pneumatic retinopexy, cryotherapy, laser retinopexy, scleral buckling or vitrectomy [2, 3]. PVR is a reparative process, similar to a keloid, initiated by full- or partial-thickness retinal breaks, retinopexy, and other types of retinal damage. It can occur from glial or retinal pigment epithelium (RPE) proliferation. Glial or RPE cells migrate to one or both surfaces of the retina, then migrate further and cover the posterior surface of the detached posterior hyaloid face [1]. Of all retinal detachment surgery cases, 5-10\% develop PVR [3].

Corticosteroids have been used as intravitreal injection after retinal detachment surgery as an adjunct to vitrectomy and silicone oil tamponade in treating PVR [4, 5]. Despite the potential benefits, intravitreal injection of triamcinolone acetonide is associated with side effects, including glaucoma, cataracts, retinal detachment, and endophthalmitis [6].

Recently, a sustained-release dexamethasone implant (Ozurdex $\left.{ }^{\circledR}\right)$ proved to be effective for the treatment of macular edema secondary to a variety of underlying diseases with a potentially lower rate of adverse events [7-9]. We report a case of rhegmatogenous retinal detachment with a high risk of PVR treated with episcleral surgery and an intravitreal dexamethasone 0.7-mg implant (Ozurdex).

\section{Case Report}

A 35-year-old Caucasian man presented with a macula-off rhegmatogenous subtotal retinal detachment extending 3 quadrants, sparing the inferior nasal quadrant, that had persisted for 1 month in his myopic left eye (fig. 1a). He had no history of previous vitreoretinal surgery, and his best corrected visual acuity was hand motion. Fifteen days before the beginning of the symptoms, he had had an ocular blunt trauma and presented with a large tear in the superior temporal quadrant extending 2 clock hours (fig. 1b), and wrinkling of the edges of the retinal tear and the inner retinal surface, denoting a grade B PVR. His medical history was unremarkable. On examination, the anterior segment was unremarkable and the intraocular pressure was normal. He underwent scleral buckling surgery with circumferential silicone sponge and an encircling silicone band, and subretinal fluid drainage was employed. Cryotherapy was performed to achieve retinopexy (fig. 2a). At the end of the surgery, he received a single intravitreal injection, via pars plana, of dexamethasone $0.7 \mathrm{mg}$ (Ozurdex) as off-label treatment (fig. 2b).

His condition has been stable for at least 9 months now, as seen on the last examination, with his best corrected visual acuity having improved to 0.2 and no sign of PVR or pucker having developed in the treated eye. No complications have been observed, including raised intraocular pressure.

\section{Discussion}

Although PVR is the most common cause of failed repair of rhegmatogenous retinal detachment, risk factors for PVR are related to several well-known pre-, intra-, and postoperative clinical situations. Girard et al. [10] identified a number of significant predictive variables: minor intra- or postoperative hemorrhage, grade A preoperative PVR, preoperative choroidal detachment, giant tears, air tamponade, detachment involving more 


\begin{tabular}{l|l}
\hline DOI: $10.1159 / 000351176$ & $\begin{array}{l}\text { C 2013 S. Karger AG, Basel } \\
\text { www.karger.com/cop }\end{array}$ \\
\hline
\end{tabular}

Reibaldi et al.: Rhegmatogenous Retinal Detachment with a High Risk of Proliferative Vitreoretinopathy Treated with Episcleral Surgery and an Intravitreal Dexamethasone 0.7-mg Implant

than 2 quadrants, cumulative break area larger than 3 optic disks, postoperative choroidal detachment, signs of uveitis at initial examination, and grade B preoperative PVR. Young age, intraocular hemorrhage before or after surgery, use of air or sulfur hexafluoride $\left(\mathrm{SF}_{6}\right)$, excessive cryotherapy, diathermy or photocoagulation, repeated surgical procedures, loss of vitreous during drainage of subretinal fluid, and the use of vitrectomy are also risk factors that increase the incidence of PVR [11].

Various pharmacological agents have shown potential benefit in reducing postoperative PVR risk, including intravitreal low-molecular-weight heparin and 5-fluorouracil [12]. Clinical reports have suggested that either systemic [13] or intravitreal [14] corticosteroids may be useful in the prevention of PVR. This was mainly attributed to their attenuating effect on the blood-retinal barrier breakdown and their inhibiting effect on the proliferation of RPE cells and fibroblasts, which are thought to be transformed RPE cells, and on myofibroblasts responsible for the contractile properties of PVR membranes. Bali et al. [15] demonstrated that adequate intraocular concentrations of dexamethasone at the time of surgery might reduce the blood-retinal barrier breakdown induced by the surgical trauma during cryotherapy, drainage of subretinal fluid, or intravitreal gas injection, and thereby decrease the incidence of PVR.

Our patient presented several risk factors that could have led to the development of PVR after retinal detachment surgery, including young age, myopia, preoperative grade B PVR, long persistence of the retinal detachment, detachment involving more than 2 quadrants and large tear. We therefore decided to inject an intravitreal dexamethasone $0.7-\mathrm{mg}$ implant (Ozurdex) after the surgery to prevent this complication. At least 9 months after surgery, no sign of PVR or pucker had developed in the treated eye.

To our knowledge, this is the first case described so far in the literature of an intravitreal dexamethasone implant inserted after episcleral surgery for rhegmatogenous retinal detachment to prevent possible PVR. This is just a case report and it has several weaknesses, including the short-term follow-up. Further investigations are needed to demonstrate the role of the intravitreal dexamethasone 0.7 -mg implant (Ozurdex) in preventing PVR after episcleral surgery and to understand the long-term treatment outcomes. Intravitreal dexamethasone $0.7-\mathrm{mg}$ implant (Ozurdex) could be considered as off-label treatment after this kind of surgery.

\section{Disclosure Statement}

The authors have no conflicts of interest to declare.

\section{References}

1 Sethi CS, Lewis GP, Fisher SK, Leitner WP, Mann DL, Luthert PJ, Charteris DG: Glial remodeling and neural plasticity in human retinal detachment with proliferative vitreoretinopathy. Invest Ophthalmol Vis Sci 2005;46:329-342.

-2 Rodriguez de la Rúa E, Pastor JC, Aragón J, Mayo-Iscar A, Martínez V, García-Arumí J, Giraldo A, SanabriaRuiz Colmenares MR, Miranda I: Interaction between surgical procedure for repairing retinal detachment and clinical risk factors for proliferative vitreoretinopathy. Curr Eye Res 2005;30:147-153.

-3 Abrams GW, Azen SP, McCuen BW 2nd, Flynn HW Jr, Lai MY, Ryan SJ: Vitrectomy with silicone oil or longacting gas in eyes with severe proliferative vitreoretinopathy: results of additional and long-term follow-up. Silicone Study report 11. Arch Ophthalmol 1997;115:335-344.

-4 Chen W, Chen H, Hou P, Fok A, Hu Y, Lam DS: Midterm results of low-dose intravitreal triamcinolone as adjunctive treatment for proliferative vitreoretinopathy. Retina 2011;31:1137-1142. 
Reibaldi et al.: Rhegmatogenous Retinal Detachment with a High Risk of Proliferative Vitreoretinopathy Treated with Episcleral Surgery and an Intravitreal Dexamethasone 0.7-mg Implant

5 Ahmadieh H, Feghhi M, Tabatabaei H, Shoeibi N, Ramezani A, Mohebbi MR: Triamcinolone acetonide in silicone-filled eyes as adjunctive treatment for proliferative vitreoretinopathy: a randomized clinical trial. Ophthalmology 2008;115:1938-1943.

6 Gillies MC, Sutter FK, Simpson JM, Larsson J, Ali H, Zhu M: Intravitreal triamcinolone for refractory diabetic macular edema: two-year results of a double-masked, placebo-controlled, randomized clinical trial. Ophthalmology 2006;113:1533-1538.

7 Herrero-Vanell R, Cardillo JA, Kuppermann BD: Clinical applications for the sustained-release dexamethasone implant for treatment of macular edema. Clin Ophthalmol 2011;5:139-146.

8 Reibaldi M, Russo A, Zagari M, Toro M, De Grande V, Cifalinò V, Rametta S, Faro S, Longo A: Resolution of persistent cystoid macular edema due to central retinal vein occlusion in a vitrectomized eye following intravitreal implant of dexamethasone $0.7 \mathrm{mg}$. Case Rep Ophthalmol 2012;3:30-34.

-9 Russo A, Avitabile T, Uva M, Faro S, Franco L, Sanfilippo M, Gulisano S, Toro M, De Grande V, Rametta S, Foti L, Longo A, Reibaldi M: Radiation macular edema after Ru-106 plaque brachytherapy for choroidal melanoma resolved by an intravitreal dexamethasone 0.7-mg implant. Case Rep Ophthalmol 2012;3:71-76. 10 Girard P, Mimoun G, Karpouzas I, Montefiore G: Clinical risk factors for proliferative vitreoretinopathy after retinal detachment surgery. Retina 1994;14:417-424.

11 Duquesne N, Bonnet M, Adeleine P: Preoperative vitreous hemorrhage associated with rhegmatogenous retinal detachment: a risk factor for postoperative proliferative vitreoretinopathy? Graefes Arch Clin Exp Ophthalmol 1996;234:677-682.

-12 Sundaram V, Barsam A, Virgili G: Intravitreal low molecular weight heparin and 5-Fluorouracil for the prevention of proliferative vitreoretinopathy following retinal reattachment surgery. Cochrane Database Syst Rev 2013;1:CD006421.

13 Koerner F, Merz A, Gloor B, Wagner E: Postoperative retinal fibrosis - a controlled clinical study of systemic steroid therapy. Graefes Arch Clin Exp Ophthalmol 1982;219:268-271.

14 Williams RG, Chang S, Comaratta MR, Simoni G: Does the presence of heparin and dexamethasone in the vitrectomy infusate reduce reproliferation in proliferative vitreoretinopathy? Graefes Arch Clin Exp Ophthalmol 1996;234:496-503.

15 Bali E, Feron EJ, Peperkamp E, Veckeneer M, Mulder PG, van Meurs JC: The effect of a preoperative subconjuntival injection of dexamethasone on blood-retinal barrier breakdown following scleral buckling retinal detachment surgery: a prospective randomized placebo-controlled double blind clinical trial. Graefes Arch Clin Exp Ophthalmol 2010;248:957-962.

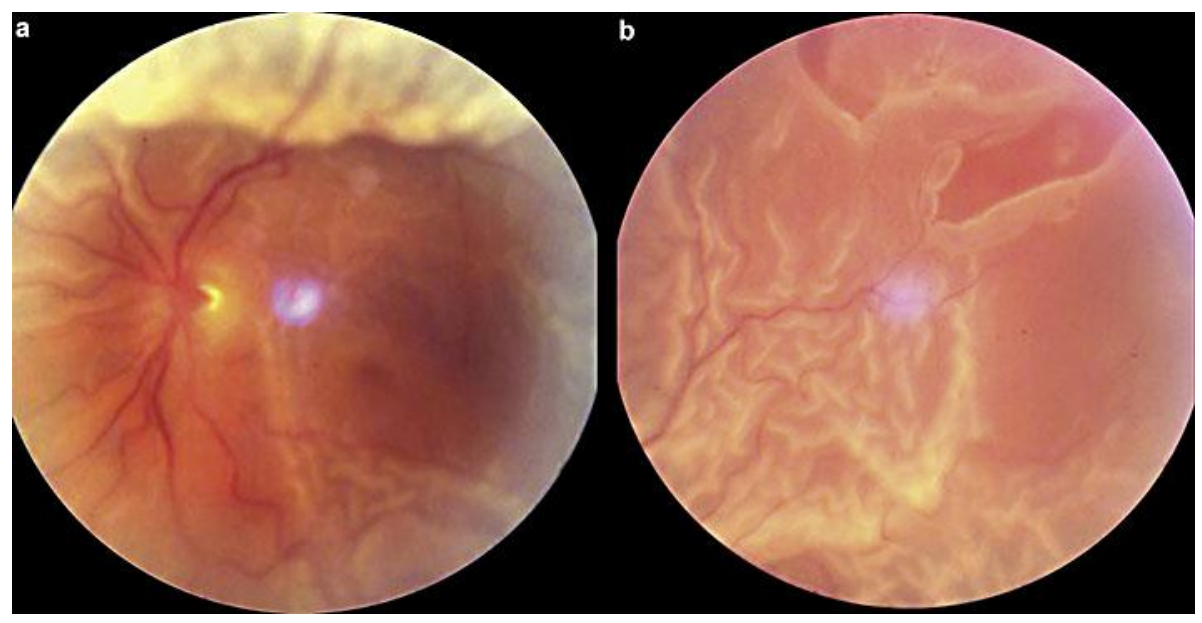

Fig. 1. a Fundus oculi before episcleral surgery and Ozurdex injection. b Large tear in the superotemporal quadrant. 
Case Reports in Ophthalmology
Case Rep Ophthalmol 2013;4:79-83

DOI: $10.1159 / 000351176$

Reibaldi et al.: Rhegmatogenous Retinal Detachment with a High Risk of Proliferative

Vitreoretinopathy Treated with Episcleral Surgery and an Intravitreal Dexamethasone 0.7-mg Implant

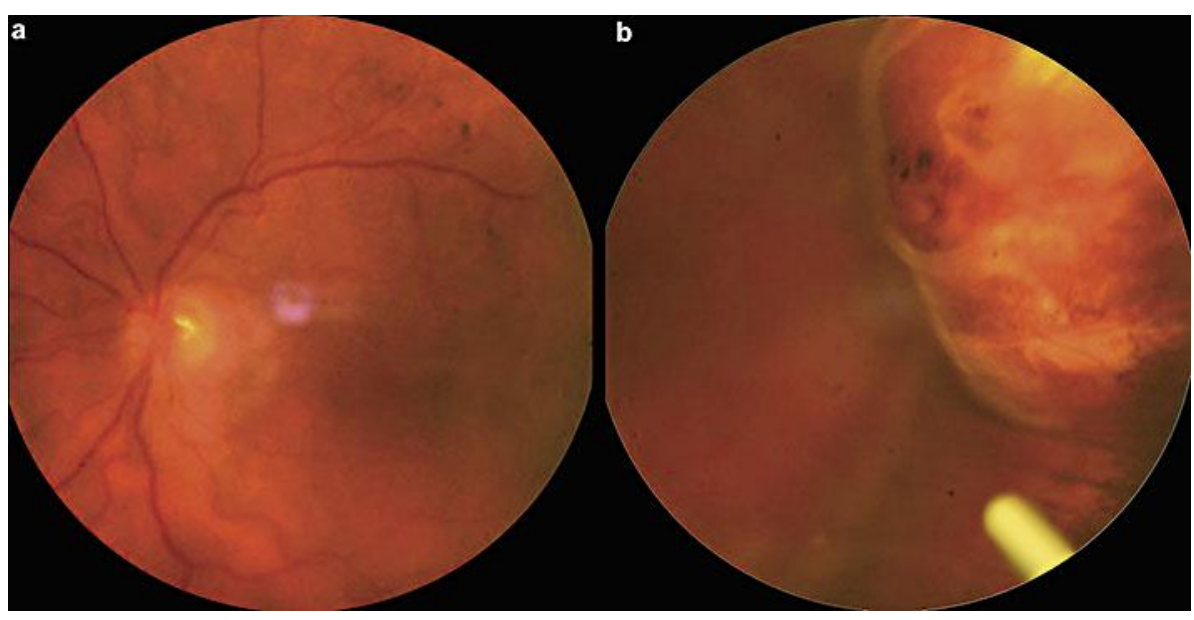

Fig. 2. a Fundus oculi following episcleral surgery. b Intravitreal Ozurdex implant. 